\title{
SITUAÇÃO LIMITE E FORMAÇÃO DOCENTE: reconfigurações pedagógicas em tempos de pandemia
}

Geniana dos Santos

Maria Gabriela Ferreira Pereira

\section{Resumo}

Este trabalho aborda o vivido no contexto da Formação de Professores, de uma Universidade Pública Brasileira. Como contingência, focaliza as mudanças nas dinâmicas de ensino e aprendizagem decorrentes da Pandemia ocasionada pelo novo Coronavírus. Para tal, problematizamos a experiência, conforme Freire (1996a, 2000) e Larrosa (2002), enfatizando aspectos de uma educação humanizadora e marcada pela esperança. No tocante à relação entre Didática e Formação de Professores, destacamos Becker (1995); Candau (2004) e Rios (2006), de modo a problematizar os modelos pedagógicos e as três dimensões básicas para a formação docente, sendo elas a Dimensão Humana, Dimensão Técnica e Dimensão Político-Social.

Palavras-chave: flexibilização; situação-limite; pandemia.

\section{LIMIT-SIT'UATION AND TEACHER'S TRAINING: pedagogical reconfigurations in pandemic times}

\begin{abstract}
This paperwork approaches what has been lived in Teacher's Training within a Brazilian Public University. As contingency, it focuses changes in teaching and learning dynamics arising from the Pandemic caused by the new Coronavirus. To do so, we problematize the experience, according to Freire (1996a, 2000) and Larrosa (2002), emphasizing aspects of a humanizing and marked by hope education. Regarding the relationship between didactics and teacher's training, we highlight Becker (1995); Candau (2004) and Rios (2006), so as to problematize pedagogical models and the three basic dimensions to teacher's training, which are the Human, the Technical and the Political-Social Dimensions.
\end{abstract}

Keywords: teaching flexibility; limit-situation; pandemic.

\section{SITUACIÓN LÍMITE Y FORMACIÓN DOCENTE: reconfiguraciones pedagógicas en tiempos de pandemia}

Resumen

Este trabajo aborda lo vivido en el contexto de la Formación Docente, de una Universidad Pública Brasileña. Como contingencia, se enfoca en los cambios en las dinámicas de enseñanza y aprendizaje resultantes de la Pandemia provocada por el nuevo Coronavirus. Para ello, problematizamos la experiencia, según Freire (1996a, 2000) y Larrosa (2002), enfatizando aspectos de una educación humanizadora y marcada por la esperanza. En cuanto a la relación entre Didáctica y Formación de Profesores, destacamos a Becker (1995); Candau (2004) y Rios (2006), con el fin de problematizar los modelos pedagógicos y las tres dimensiones básicas para la formación docente, siendo la Dimensión Humana, Dimensión Técnica y Dimensión Político-Social.

Palabras clave: flexibilización de la enseñanza; situación límite; pandemia. 


\section{INTRODUÇÃO}

A pandemia ocasionada pelo novo coronavírus instituiu uma realidade atípica, uma situação-limite que transcende a condição individual da vida cotidiana, provocando mudanças coletivas na nossa forma de existir e agir no mundo. Como situação-limite, entendemos, a partir de Freire (2000), aqueles momentos de difícil vivência pelos homens e que só podem ser superados na relação homem-mundo. Em face a tais momentos, os homens operam em atos-limite, produzindo ações voltadas à superação e à negação de uma determinada realidade (FREIRE, 2000; COSTA e FURTADO, 2015).

Neste trabalho, ao resgatarmos a noção de situação-limite a partir de Freire (2000), mobilizamos alguns sentidos da formação docente situada nas concretudes da vida atual, circunstanciada, por exemplo, pela pandemia. Entendemos que, nesse contexto, demandamos uma reflexão acerca dos atos-limite de enfrentamento e humanização das práticas educativas. Conforme Tauchen et al. (2003, p. 3), “[...] os limites reais são de todos, não são só individuais, pois afetam a comunidade inteira".

Observamos, atualmente, uma insistente ação de continuidade das práticas educativas, em que o adoecimento, a morte e o luto são negligenciados em prol da construção de um "novo normal". Desse modo, percebemos que embora seja interessante a manutenção dos vínculos entre os estudantes e a universidade, e, sobretudo, entre os estudantes e seus professores, as práticas educativas necessitam estar direcionadas à formação humanizadora enquanto projeto coletivo, com vistas a superação da situaçãolimite vivenciada (TAUCHEN et al., 2003).

Devido às inúmeras medidas de segurança instauradas pelas organizações responsáveis pelo controle e monitoramento da curva de contaminação pelo novo coronavírus, diversas atividades sociais foram desestimuladas e, durante um curto período, proibidas. Nesse aspecto, há que se reconhecer que o fato de ficarmos em casa contribuiu para a diminuição da contaminação, para a baixa do índice de leitos ocupados em algumas regiões e, por conseguinte, para a redução de óbitos, que poderiam ter sido ainda maiores que o registrado.

Contudo, observamos também um misto de esperança e desencantamento pelo mundo, um "entregar os pontos", impulsionado pelas necessidades da economia e da agressiva lógica do consumo. Nesse bojo, muitas pessoas desistiram do distanciamento, assumiram um discurso negacionista, acelerando a contaminação entre as pessoas, e a mutação do vírus, que já conta com variantes.

No contexto de adoecimento, morte e incerteza quanto ao futuro, muitas áreas foram obrigadas a reorganizar a prestação de serviço à comunidade, dentre elas, destaca-se a área educacional, com diferentes atos-limite, quer seja na Educação Básica quer seja no Ensino Superior.

Grande foi o debate sobre a paralisação das atividades educativas no início de 2020, posteriormente, muitos embates em torno da continuidade das atividades educativas puderam ser acompanhados. Uma das pautas discutidas se relacionava à ausência de compreensão sobre as modalidades presencial e a distância. Outra, bastante problematizada, referia-se aos direitos educacionais: acesso, permanência e qualidade nos novos moldes de oferta.

No ano de 2021, outros temas foram sendo agregados ao cenário de disputas. A forma de oferta, o ensino remoto, o ensino híbrido, o domínio das tecnologias e os modelos diretivo e não diretivo de ensino são alguns exemplos. Nesse sentido, ainda que seja perceptível a grande pressão para o retorno presencial, existindo o bom senso, sem a ampliação da vacinação e com os indícios de uma terceira onda de contaminação, as atividades educativas continuarão atreladas à oferta remota e mediada pelas Tecnologias da Informação e Comunicação (TICs), conforme já autorizado pelo Conselho Nacional da Educação. 
Considerando o exposto, buscamos, neste trabalho, operar com o sentido de esperança evocado por Freire (2000), conectando-o à necessária construção de agendas educacionais humanizadoras, que, especialmente, considerem o grande número de estudantes que se encontram impossibilitados de estudar. Nesse tocante, embora consideremos a situação-limite vivenciada a partir da pandemia, defendemos que "sem um mínimo de esperança, não podemos sequer começar o embate" (FREIRE, 2000, p. 6).

A partir do relato de experiência, realizamos uma reflexão acerca do vivido em 2020, no âmbito da formação para a docência. Para tal, organizamos o presente texto em tópicos, sendo eles: Relato de experiência - um olhar sobre o vivido; Flexibilização do ensino; Dimensões da formação docente; Relato 1 - uma experiência discente; Relato 2 - uma experiência docente.

Tais tópicos procuram apresentar o relato de experiência como uma potente ferramenta metodológica formativa aos licenciandos que se preparam para atuar na docência de Educação Básica em um cenário de incertezas e transformações nos modos de mediação pedagógica, na organização escolar e por meio do ensino remoto.

\section{RELATO DE EXPERIÊNCIA - UM OLHAR SOBRE O VIVIDO}

A narrativa é uma das ações mais antigas já realizadas pelo ser humano. A partir dela, o homem organiza, reflete e modifica a realidade vivida, principalmente olhando para as ações do passado e vislumbrando um futuro diferente, mais próximo ao sonhado no movimento de esperançar.

Narrar implica um trabalho com as palavras, com o campo simbólico, de produção de sentido e disputa por significação. Conforme Larrosa (2002, p. 20-21), “[...] as palavras produzem sentido, criam realidades e, às vezes, funcionam como potentes mecanismos de subjetivação".

Organizar o passado, rememorando-o, é também uma oportunidade para estruturar a capacidade reflexiva sobre as ações cotidianas, sendo o ato de narrar uma ação que possibilita uma projeção melhor do futuro, um planejamento mais elaborado daquilo a ser realizado. Desse modo, quando narramos, não apenas contamos algo para alguém, mas recriamos uma situação a partir de um aspecto que foi vivenciado de um modo significativo por um sentido específico evocado a partir da experiência, o que possibilita um movimento de ressignificação.

As palavras com que nomeamos o que somos, o que fazemos, o que pensamos, o que percebemos ou o que sentimos são mais do que simplesmente palavras. E, por isso, as lutas pelas palavras, pelo significado e pelo controle das palavras, pela imposição de certas palavras e pelo silenciamento ou desativação de outras palavras são lutas em que se joga algo mais do que simplesmente palavras, algo mais que somente palavras. (LARROSA, 2002, p. 21)

A criação de uma cena textual permite ao sujeito um movimento em direção aos princípios de autoria/autonomia, da responsabilização, uma vez que, ao narrar sua própria história em um contexto específico, o sujeito imprime uma perspectiva própria, assumindo lugar central na cena construída.

Conforme Larrosa (2002), narrar é uma ação capaz de produzir sentido ao vivido, a tudo aquilo que nos acontece e que nos toca de algum modo. Assim, quando decidimos narrar, o fazemos sobre aquilo que nos marcou de alguma maneira, enquanto acontecimento de vida, fez com que sentíssemos algo, afetando-nos profundamente.

Desse modo, recorremos à experiência para resgatarmos sentidos que se fizeram marcantes, definindo a perspectiva do vivido como promotora de reflexão e transformação. A experiência, para Larrosa (2002, p. 21), "[...] é o que nos passa, o que nos acontece, o que nos toca. Não o que se passa, 
não o que acontece, ou o que toca. A cada dia se passam muitas coisas, porém, ao mesmo tempo, quase nada nos acontece".

O relato da experiência adotado neste trabalho mostra-se importante para que possamos registrar um vivido, sentido e refletido no âmbito da formação docente. Mas, sobretudo, para que possamos construir uma abertura de trabalho com a palavra em face da continuidade da vida acadêmica em tempos de adoecimento e morte.

Apresentamos, a seguir, uma descrição da experiência vivida durante a oferta de ensino remoto em uma universidade pública brasileira. Nesse sentido, resgatamos algumas informações capazes de contextualizar o processo de flexibilização educacional ocorrido durante o ano de 2020 no espaço de aprendizagem em foco.

\section{FLEXIBILIZAÇÃO DO ENSINO}

$\mathrm{Na}$ Universidade Federal de Mato Grosso (UFMT), a flexibilização foi discutida e organizada após debates e dissenso. De início, houve intenso empenho em enfatizar que essa forma de oferta, marcada pela provisoriedade de um "novo normal", não poderia ser confundida com a modalidade Ensino a Distância (EAD), em que uma estrutura de organização pedagógica é mobilizada para o acompanhamento e orientação dos estudantes.

Diálogos tangenciados pelos posicionamentos pró e contra flexibilização foram ganhando e perdendo força à medida que o tempo foi passando e a universidade foi sendo chamada a dar respostas pela sua "aparente paralisação".

Ao passo que os debates ocorriam, foi ofertado um curso para preparar os professores para a construção/modelagem do Ambiente Virtual de Aprendizagem (AVA). Em tal curso, voltado para a autoria na produção de materiais didáticos pedagógicos, os docentes tiveram maior contato com as ferramentas do AVA, sendo esse momento acompanhado pela Secretaria de Tecnologia Educacional da Universidade (SETEC/UFMT).

Ainda em meio às polêmicas, por meio da Resolução do Conselho de Ensino, Pesquisa e Extensão (CONSEPE N. ${ }^{\circ} 32$ de 08 de julho de 2020), ficou definida

[...] a regulamentação da flexibilização de componentes curriculares em caráter excepcional e temporário, e sobre o desenvolvimento de estratégias de ensinoaprendizagem por meio de Tecnologias da Informação e Comunicação e outros instrumentos em substituição e/ou complementação às estratégias presenciais, para o ensino de graduação no período de suspensão das atividades presenciais. (UFMT, 2020)

No referido contexto, os cursos puderam optar pela oferta de disciplinas mediante a flexibilização, conforme exposto a seguir, a partir da orientação do CONSEPE:

$\int 1^{\circ} \mathrm{A}$ unidade acadêmica interessada na oferta dos componentes curriculares de que trata o caput deverá manifestar interesse à Pró-Reitoria de Ensino de Graduação (PROEG) da UFMT, encaminhando o Formulário de Planejamento de Oferta das Atividades (ANEXO I) devidamente aprovado pelo Colegiado de Curso e homologado pela Congregação, por meio de processo disponibilizado no Sistema Eletrônico de Informação (SEI). (UFMT, 2020)

Ainda que a universidade tenha decidido acerca da oferta, no contexto de cada curso, a adesão dos docentes à flexibilização foi livre, de modo que uma organização interna foi realizada para 
atendimento aos estudantes que, igualmente, puderam optar por participar dessa dinâmica de oferta das disciplinas.

\section{DIMENSÕES DA FORMAÇÃO DOCENTE}

Temos aprendido que a formação docente ocorre a partir das três dimensões básicas: dimensão humana (ética), dimensão técnica e dimensão político-social. Tais aspectos são discutidos por vários autores, como Freire (1996a), Candau (2004) e Rios (2006), que salientam a necessidade formativa dos professores situada nas contingências reais da vida e na resposta crítica para a atuação profissional.

A formação da dimensão humana (ética) pode acontecer a partir do diálogo, da construção de relações respeitosas pautadas na empatia e na consideração mútua. Ela se caracteriza pela relação estabelecida na sala de aula, ainda que recontextualizada virtualmente, pois pode estimular o interesse do aluno em algum conhecimento ou simplesmente possibilitar o vínculo afetivo com sua turma, permitindo um desenvolvimento individual, mas também coletivo.

A sala de aula compreende um espaço no qual se estabelecem relações. Faz-se necessário que o professor tenha consciência das contradições e dos desafios que permeiam sua prática pedagógica e que tenha como compromissos a transformação social e a busca de práticas educativas que se ajustem aos princípios de construção do conhecimento. (GONZAGA, CASTANHO e MACHADO, 2011, p. 25)

Conforme sinaliza Freire (1996a), o bom professor é o que consegue trazer o estudante para o movimento do pensar, estabelecendo uma reciprocidade proveitosa para a construção do conhecimento. $\mathrm{Na}$ dimensão humanizadora, o futuro professor descobre elementos que não só dizem respeito a sua própria condição, mas compreende o lugar do estudante com quem se encontrará no futuro, promovendo a atenção e a sensibilidade para a condição concreta de vida de cada um. A humanização da educação e do professor em sua formação é um princípio não só importante, mas fundamentalmente necessário em tempos como o vivenciado.

Essa dimensão nos faz perceber que não é possível seguir com o planejamento, cumprindo um programa enquanto as pessoas adoecem e morrem muito perto de nós. Há um tempo da vida, atravessado pela morte, a morte de um colega, de um professor, de um conhecido, que requer elaboração, luto e cuidado. Em muitos aspectos, a educação pode ser vista como uma profissão do cuidado, da atenção ao outro, como ensinava Paulo Freire.

Além da formação humana, sensível e atenta, o momento presente exige uma reinvenção do conhecimento técnico, central na mediação pedagógica atual. A formação na dimensão técnica objetiva os melhores meios de assistência para possibilitar um efetivo aprendizado por parte dos alunos, seja dentro ou fora de sala de aula.

Para Rios (2006, p. 94), “[...] a dimensão técnica deve servir de suporte para a competência, uma vez que essa se revela na ação dos profissionais [...]”. Estes meios perpassam desde os objetivos instrucionais, a seleção do conteúdo, as estratégias de ensino até a avaliação em que os docentes se preparam para suas práticas pedagógicas. Essas aprendizagens vinculam experiências práticas e teóricas vivenciadas pelos estudantes, demandam tempo para a compreensão e, por sua complexidade, tendem a ser simplificadas na estrutura de ensino remoto.

Essas duas dimensões mencionadas anteriormente se articulam a uma formação política, necessária ao futuro professor, pois possibilita uma atuação reflexiva do trabalho docente junto à 
sociedade. A dimensão político-social nos permite compreender que a educação não é um processo neutro, pois opera na manutenção ou transformação social.

Tais aspectos articulados foram discutidos por Candau (2004) na sua proposta multidimensional da didática. A autora destaca que, por vivermos em uma sociedade, influenciamos e somos influenciados pelas diversas ações que delineiam sua conservação ou transformação. Nesse sentido, a profissão docente não é neutra, pois não se institui de modo alheio às contingências concretas da vida (FREIRE, 2000).

A partir dessa vivência de uma docência construída historicamente, podemos vislumbrar o processo de transformação educacional e da própria sociedade.

Conforme Freire (1979, p. 27)

No momento em que os indivíduos, atuando e refletindo, são capazes de perceber o condicionamento de sua percepção pela estrutura em que se encontram, sua percepção muda, embora isto não signifique, ainda, a mudança da estrutura. Mas a mudança da percepção da realidade, que antes era vista como algo imutável, significa para os indivíduos vê-la como realmente é: uma realidade histórico-cultural, humana, criada pelos homens e que pode ser transformada por eles.

As vivências, sejam elas docentes ou discentes, estão intimamente ligadas ao ambiente de sala de aula, ainda que virtual. Isso significa dizer que ambos aprendem na relação, na troca, na partilha. Os professores não somente ensinam como também adquirem as diversas experiências vividas com seus alunos e vice-versa. Cada ser humano em si carrega valores e conceitos aprendidos e experienciados no ambiente familiar, em rodas de amigos e até mesmo dentro do próprio meio escolar ou acadêmico.

Embora a competência técnica seja fundamental para que o docente consiga trabalhar em prol da construção de conhecimento escolar, neste momento de pandemia, juntos aos estudantes, é preciso retomar um sentido humano da educação, pautado na pedagogia relacional (BECKER, 1995).

Tendo em vista o que defendia Paulo Freire sobre o ensino, para inibir o reducionismo da formação docente a uma nova versão da educação bancária, pautada no domínio da tecnologia e acúmulo de informações disponíveis em plataformas, é preciso um investimento nos processos de humanização do ensino flexibilizado, com vistas a manutenção e melhorias do vínculo entre os sujeitos da aprendizagem, professores e estudantes.

Recordando Freire (1996a, p. 13)

É neste sentido que ensinar não é transferir conhecimentos, conteúdos nem forrar é ação pela qual um sujeito criador dá forma, estilo ou alma a um corpo indeciso e acomodado. Não há docência sem discência, as duas se explicam e seus sujeitos, apesar das diferenças que os conotam, não se reduzem à condição de objeto, um do outro. Quem ensina aprende ao ensinar e quem aprende ensina ao aprender. Quem ensina, ensina alguma coisa a alguém.

Desta forma, entendemos que os atos de aprender e ensinar estão entrelaçados, independentemente do contexto em que possam ocorrer. É notório que, ao longo do tempo, os seres humanos sempre estiveram imersos nesta sistemática de que não existe aprendizado sem ensino, tal como afirmou Freire (1996a, p.12):

Ensinar inexiste sem aprender e vice-versa e foi aprendendo socialmente que, historicamente, mulheres e homens descobriram que era possível ensinar. Foi assim, socialmente aprendendo, que ao longo dos tempos mulheres e homens perceberam que era possível - depois, preciso - trabalhar maneiras, caminhos, métodos de ensinar. 
Aprender precedeu ensinar ou, em outras palavras, ensinar se diluía na experiência realmente fundante de aprender. Não temo dizer que inexiste validade no ensino de que não resulta um aprendizado em que o aprendiz não se tornou capaz de recriar ou de refazer o ensinado, em que o ensinado que não foi apreendido não pode ser realmente aprendido pelo aprendiz.

O aprendizado está diretamente relacionado ao que cada sujeito vive ou viveu desde seu nascimento e se prolonga com as experiências formais de aprendizagem vivenciadas na escola. Como defendia Paulo Freire, nesta relação entre professor-aluno, é preciso que haja um encontro entre as diferentes leituras de mundo, especialmente em um mundo como o vivenciado atualmente.

Respeitar a leitura de mundo do educando significa tomá-la como ponto de partida para a compreensão do papel da curiosidade, de modo geral, e da humana, de modo especial, como um dos impulsos fundantes da produção do conhecimento. É preciso que, ao respeitar a leitura do mundo do educando para ir mais além dela, o educador deixe claro que a curiosidade fundamental à inteligibilidade do mundo é histórica e se dá na história, se aperfeiçoa, muda qualitativamente, se faz metodicamente rigorosa. E a curiosidade assim metodicamente rigorizada faz achados cada vez mais exatos. No fundo, o educador que respeita a leitura de mundo do educando, reconhece a historicidade do saber, o caráter histórico da curiosidade, desta forma, recusando a arrogância cientificista, assume a humildade crítica, própria da posição verdadeiramente científica. (FREIRE, 1996a, p. 63)

Isto é válido para todos os momentos formativos, principalmente para o que estamos vivendo agora, com o isolamento social causado pelo coronavírus que, como já mencionado, impossibilitou as aulas presenciais na Educação Básica e no Ensino Superior, sendo o ensino remoto a forma mais viável para a continuidade das atividades educacionais e, sobretudo para o espaço da partilha das angústias vivenciadas.

Entendemos, a partir de Gonzaga, Castanho e Machado (2011, p. 25), que

[...] no cenário atual da educação não há espaço para a desarticulação das dimensões política, ética e técnica no processo de ensino e aprendizagem, pois cada uma dessas dimensões tem sua importante contribuição para esclarecer o papel sociopolítico da educação, da escola e, mais especificamente, do ensino e da aprendizagem. É um fazer pedagógico no sentido de ir além dos métodos e das técnicas, procurando associar teoria e prática, conteúdo e estratégia, ensino e pesquisa, professor e aluno, escola e sociedade, bem como as dimensões técnico-política e ético-técnica.

A contingência vivenciada também torna saliente uma realidade em que muitos estudantes, por utilizarem muito mais recursos tecnológicos, conhecem as tecnologias de forma mais profunda que os próprios professores, algo que coloca os professores em um lugar de não saber, demandando paciência, auxílio mútuo e empatia.

Somado a esse aspecto, há que se considerar que muito do conhecimento adquirido pelos estudantes em torno da tecnologia, por meio das informações disponíveis na internet sobre os conhecimentos formais ou por uma vivência mediada pelas ferramentas tecnológicas, nem sempre torna a atuação sobre esses meios mais reflexiva, já que muitas vezes esses conhecimentos não são convertidos em ferramenta pedagógica reflexiva e de aprendizagem.

Nesse sentido, ter acesso à informação não torna dispensável a mediação realizada pelos professores, imprescindível para a humanização no processo de construção de conhecimento, conforme ensina Larrosa (2002, p. 21-22): 
A informação não é experiência. E mais, a informação não deixa lugar para a experiência, ela é quase o contrário da experiência, quase uma antiexperiência. Por isso a ênfase contemporânea na informação, em estar informado, e toda a retórica destinada a constituirmos como sujeitos informantes e informados; a informação não faz outra coisa que cancelar nossas possibilidades de experiência. O sujeito da informação sabe muitas coisas, passa seu tempo buscando informação, o que mais o preocupa é não ter bastante informação; cada vez sabe mais, cada vez está melhor informado, porém, com essa obsessão pela informação e pelo saber (mas saber não no sentido de "sabedoria", mas no sentido de "estar informado"), o que consegue é que nada lhe aconteça.

A partir da vivência de estudos no período de flexibilização do ensino, entendemos que a rotina de muitos não se assemelhava, muitos estudantes e professores desenvolveram outras atividades de pesquisa e ensino que se somaram aos afazeres relacionados ao cuidado familiar, outros ainda faziam parte de grupo de risco ou passaram pelo adoecimento enquanto estávamos estudando.

Todos esses aspectos, somados ao fato de que a onda de contágio aumenta no início de 2021, algo potencializado pela ausência de assistência médica nos hospitais, torna imperiosa a continuidade da flexibilização do ensino, destacando, sobretudo, a necessária reflexão sobre um fazer que não apenas dá continuidade às atividades acadêmicas enquanto não podemos voltar ao presencial, mas que reestrutura a reflexão que temos sobre ensino, aprendizagem, aula e, principalmente, sobre a intencionalidade formativa na direção da humanização.

É necessário pensarmos outros contornos, outros sentidos para o acesso, a permanência e a qualidade, tendo em vista os estudantes que, por diversas questões, continuam impossibilitados de seguirem com os estudos e de se relacionarem no AVA. Esses estudantes, pressionados pelas questões econômicas familiares, pelo desemprego, pela ausência de recursos para custear o acesso à internet, entre outras questões, tendem a evadir, o que torna urgente ações de inclusão (digital) para o Ensino Superior.

Considerando a continuidade da flexibilização, acreditamos que a atenção às dimensões formativas pode auxiliar na redução dos equívocos relacionados ao repasse de um aglomerado de conteúdo/informação em detrimento ao olhar humanizado para os sujeitos desse processo, futuros professores da Educação Básica.

Destacamos que na UFMT houve todo um cuidado para que as dimensões humana, técnica e político-social estivessem presentes nessa nova forma de mediação pedagógica, contingenciada pela pandemia. Nas práticas pedagógicas observadas, houve, além do esforço de utilizar a tecnologia em prol da mediação pedagógica, um investimento na pedagogia relacional (BECKER, 1995).

Ainda assim, foi notória a sobrecarga de trabalho que a mediação tecnológica provocou nos sujeitos (professores e estudantes), principalmente em função da tentativa de manter a qualidade formativa, associando esse significante à dinâmica de ensino presencial. Ao observarmos retrospectivamente, o fato de estarmos em casa imprimiu uma lógica compensatória, em que fomos abruptamente acessados a qualquer momento para o trabalho. Nesse sentido, toda a organização laboral construída culturalmente foi e tem sido fragilizada. Parece haver uma associação direta entre estar em casa e descansar, essa significação, para o trabalhador e para o estudante tem se mostrado precária, em uma tensa relação opressor-oprimido levada ao limite da produtividade intelectual.

\section{Relato 1 - uma experiência discente}

Como estudante do terceiro ano do curso de pedagogia pela Universidade Federal de Mato Grosso, e futura professora da Educação Básica, compartilho um pouco de minha experiência durante o 
ensino flexibilizado. Penso que tal registro possa contribuir um pouco mais para novas percepções sobre o ensino-aprendizagem da docência no contexto atual.

Em nosso espaço formativo, muitos foram os debates sobre o retorno ou não das aulas no modo online, em vista de uma grande discussão de como ficariam os discentes que não dispunham de recursos, considerando uma parcela significativa de estudantes que são originários de outros estados ou moram em lugares onde não há a possibilidade de acesso à internet e a computadores. Isso tudo, inclusive, é parte considerável do perfil e da realidade dos estudantes das licenciaturas, futuros professores.

Com a instauração das diretrizes para a oferta flexibilizada, cada unidade, departamento, curso, professor e estudante da universidade pôde optar ou não por participar do processo de flexibilização do ensino. No meu curso, das 12 disciplinas obrigatórias em que estava matriculada, apenas três foram flexibilizadas. Dentre as optativas que contam na grade curricular, apenas uma foi flexibilizada. Com ausência de opções, procurei inscrever-me em outra disciplina, de modo a completar minha carga horária.

Percebi um pouco de dificuldade na adaptação para o ensino remoto, identificando que algumas disciplinas estavam planejadas para o ensino presencial. Nosso comportamento também demorou um pouco para se modificar, principalmente devido ao fato de estarmos acostumados com a dinâmica da presencialidade, com o contato com o professor e com a relação entre teoria e prática, sempre promovida em sala de aula.

Além disso, muitos estudantes estavam pouco familiarizados com as ferramentas tecnológicas que, na oferta presencial, eram pouco acessadas. Com o intuito de contribuir para a nossa capacidade de utilizar os recursos que seriam empregados nas aulas, a universidade disponibilizou um curso de introdução ao Ambiente Virtual de Aprendizagem.

No meu caso, disponho de internet, que por vezes é instável, e meu notebook possui algumas limitações, mesmo assim, fiz o possível para participar das aulas síncronas e adaptar-me aos novos recursos que não conhecia. No início, participava somente pelo chat de mensagens do AVA, pois não conseguia ligar o microfone no celular. Participava pelo celular devido ao áudio do meu notebook ser muito baixo para falar, o que vim a aprender depois como adequar. Um ponto que destaco, no caso de minha turma, foi a compreensão e empatia de alguns dos professores com relação às nossas dificuldades no uso das ferramentas tecnológicas.

Como cursei todas as disciplinas que foram flexibilizadas, confesso que me senti sobrecarregada, tanto fisicamente como psicologicamente. De modo geral, não havia somente aulas para participar, atividades para realizar e textos para ler, tinha e ainda tenho outras demandas, negligenciadas pela temporalidade instituída nas dinâmicas de estudo síncrono-assíncrono.

Infelizmente, com as aulas remotas, tudo é feito de modo mais acelerado, realizamos duas, três coisas ao mesmo momento, as aulas nos fizeram perder o real significado de tempo do ensinoaprendizagem, da reflexão, da construção de uma relação entre o que fazemos e o que pensamos sobre esse fazer.

\section{Relato 2 - uma experiência docente}

Optei por participar da flexibilização em seu primeiro momento de oferta, tendo em vista a oportunidade de compreender esse momento específico da construção de práticas pedagógicas no país, para além de um dia recordá-lo pela via teórica. A isso, soma-se o fato de várias escolas de Educação Básica em nossa região continuarem suas atividades por meio do uso das tecnologias, algo que provocou a curiosidade em entender os problemas e as dificuldades ocasionados quanto à garantia dos direitos ao 
acesso, à permanência e qualidade tão problematizados em produções acadêmicas (GOLDEMBERG, 1993; SAVIANI, 2013).

No caso do curso em que atuei, a procura pelas disciplinas pedagógicas foi alta, o que impactou a formação das turmas. O número de estudantes ultrapassou 60 , algo igualmente observado em outras disciplinas pedagógicas ofertadas. A justificativa, no geral, era que tais disciplinas eram teóricas, uma representação bastante veiculada entre os cursos de licenciatura.

Para auxiliar os docentes, a coordenação do curso criou uma comissão, bem como um grupo no aplicativo WhatsApp. Um aspecto a ser ressaltado refere-se à necessidade de modelagem da disciplina na plataforma de aprendizagem institucional, assim como o funcionamento dos momentos síncronos e assíncronos, definidos por cada docente.

No meu caso, mesmo possuindo familiaridade com o uso das tecnologias nos processos de mediação da aprendizagem, a experiência do uso intensivo das ferramentas tecnológicas não consistiu em tarefa simples. Ao iniciar a disciplina, busquei mesclar momentos síncronos e assíncronos para condução das atividades. Nesse tocante, saliento que essa divisão pouco funcionou, sendo os encontros síncronos imprescindíveis para a produção do diálogo acerca dos temas abordados na disciplina.

Ainda sobre esse aspecto, a presencialidade (virtual) nos momentos síncronos foi bastante prejudicada, desvelando dilemas de ordem estrutural, por exemplo, ausência de conexão (internet), minha e dos estudantes, ausência de computadores, pois muitos estudavam e continuam estudando pelo celular, ausência de condição emocional para estudar/trabalhar (minha e dos estudantes) enquanto enfrentávamos problemas relacionados ao adoecimento.

Essa dicotomia, momentos síncronos e assíncronos, viabilizou o acesso dos estudantes aos conhecimentos propostos na disciplina, em momentos diferentes, uma vez que a aula passou a ser gravada e "armazenada" na plataforma institucional. Todavia, isso ocasionou a primeira dificuldade, visto que a própria estrutura de uma aula gravada indica a exposição de alguns conteúdos, de modo a ocasionar desafios à disciplina, que procura ressignificar práticas pedagógicas tradicionais e diretivas no contexto do ensino.

Nesse tocante, optei pela aula expositiva dialogada, com texto-base para estudo em cada aula em um primeiro momento, inserindo, após esse início, atividades e estratégias que oportunizassem maior participação e reflexão dos estudantes. A primeira estratégia com efeito positivo para a turma em questão foi a utilização do mapa conceitual para organização e direcionamento da aula.

A solicitação do mapa garantiu maior discussão no momento da aula a partir da síntese preparada por eles. Entretanto, essa estratégia somente obteve resultado satisfatório após a terceira tentativa. Outra estratégia utilizada para dinamização da aula foi articular a aula invertida e a aula expositiva dialogada. Assim, ao final de cada aula, alguns estudantes, presentes no momento síncrono, encarregavam-se de uma parte da aula, uma atividade, uma temática, uma pesquisa, de modo a tornar o momento/aula síncrono um pouco mais dialógico ${ }^{1}$.

A esse respeito, saliento que os estudantes, por estarem cursando uma disciplina que visa preparálos para a atuação pedagógica, aceitaram os acordos sem nenhuma contestação, demonstrando curiosidade acerca das metodologias possíveis para a construção de uma aula na contingência vivenciada. A reflexão, nesses encontros/aulas, buscou problematizar tais aspectos para que eles não se tornassem espaços de aplicação, mas sim momentos de problematização acerca das práticas pedagógicas potencializadoras no contexto da Educação Básica.

\footnotetext{
${ }^{1}$ Recentemente, em um momento síncrono disponibilizado para estudo de Paulo Freire, uma de minhas alunas destacou:

"assistir aula gravada é triste, solitário e não dialógico, não é Profa.?”
} 
Conquanto esses momentos/aulas tenham sido produtivos para a construção das aprendizagens dos estudantes, algumas características a respeito da oferta flexibilizada devem ser destacadas, pois consistem em desafios para a prática docente direcionada à educação problematizadora e à formação reflexiva:

1. Assim como nos encontros presenciais, um grupo de estudantes se mostrou mais participativo nos momentos síncronos, e essa participação possibilitou falar da didática para além de seu aspecto histórico ou teórico. Contudo, essa participação por parte de alguns não conseguiu potencializar a superação do silenciamento de estudantes que, mesmo estando online, comportaram-se como espectadores de aula, comportamento justificado e reforçado pelas possibilidades de retirada de imagem, entrada na plataforma na condição de ouvinte, problemas de conectividade, entre outros.

2. A ausência nos momentos síncronos, possibilidade garantida aos estudantes, tem gerado dificuldades para o acompanhamento das aprendizagens.

3. A produção do diálogo e a orientação para o estudo, que no AVA está restrito à correção/avaliação/devolutiva, refacção de atividades, demanda, do docente, maior tempo destinado ao feedback com relação às diferentes postagens (fóruns, mensagens, chats, tarefas).

4. A utilização da plataforma como repositório de atividades, sem que haja compreensão dos instrumentos de acompanhamento e mediação das aprendizagens, denota uma significação de currículo como programa a ser executado, privilegiando um conjunto de conhecimento a ser repassado/transmitido, podendo contribuir para um retorno de práticas educativas tradicionais, diretivas e pouco problematizadoras, que no molde flexibilizado é difícil de ser superado.

Esses pontos supracitados evidenciam a necessidade de reflexão acerca da continuidade da oferta contingencial de disciplinas de modo flexibilizado, com critérios de acompanhamento da aprendizagem, para além da correção de atividades que demonstram a assimilação de conteúdos postados em uma plataforma.

Essa ação de leitura, estudo e produção de atividades, antes acessória e complementar ao ensino superior presencial, por meio do AVA, devido ao "novo normal", passou a ser central, constituindo a espinha dorsal da proposta de ensino flexibilizado.

Considerações finais

Neste trabalho, procuramos evidenciar, a partir da experiência vivida no período de flexibilização do ensino, que a pandemia trouxe consigo uma situação-limite coletiva, provocando uma nova vivência com relação a diferentes áreas da vida cotidiana, marcadas pela esperança-desesperança (FREIRE, 2000). Nesse sentido, entendemos que a flexibilização do ensino foi uma ferramenta para manutenção do vínculo entre estudantes e universidade.

A partir de uma difícil vivência pedagógica, marcada pelo adoecimento/morte, pela mediação tecnológica e pela dependência de conectividade, foi possível compreender a diferença entre a simples apropriação de informações sobre determinados assuntos e a mediação pedagógica dos professores, necessária para a aprendizagem de como ser docente, um agente humanizador, também em situaçõeslimite (LARROSA, 2002; FREIRE, 2000).

Identificamos muitas limitações nesse modo de organização e mediação pedagógica, sendo a principal delas a ausência de compreensão sobre as temporalidades do ensino-aprendizagem em uma perspectiva pedagógica relacional e humanizadora.

Isso pois, embora o ensino remoto tenha possibilitado a proximidade entre diferentes sujeitos e a universidade, também evidenciou/aumentou ainda mais inúmeras desigualdades com relação ao acesso e à permanência desses estudantes em espaços de aprendizagem no Ensino Superior. 
Ademais, a significação de remoto nesse período, que poderia ser atrelada aos sentidos de segurança e conciliação entre momentos de cuidado com a saúde e estudos/trabalho, assumiu uma faceta de extrapolação dos limites e espaços em que as relações de trabalho ocorrem em nossa sociedade, gerando sobrecarga e esgotamento aos sujeitos do ensino-aprendizagem. Assim, com a possibilidade do trabalho online, a expropriação do tempo de vida dos sujeitos foi ainda mais intensificada.

O que levamos como aprendizado deste período tão delicado é que, em meio às incertezas que ainda nos esperam, o ensino remoto, por hora, apresenta-se como uma possibilidade de vínculo, um instrumento de esperança em meio à longa trajetória que ainda vivenciaremos. Contudo, o processo de flexibilização do ensino exige atos-limite relacionados ao acolhimento, à escuta dos estudantes e professores acerca de suas circunstâncias concretas, além da compreensão de que sua significação de qualidade não deve relacionar-se ao volume de informações disponibilizadas no AVA e, tampouco à quantidade de tempo online, forma de normatização e controle do trabalho desenvolvido em tempos de pandemia, tendo como critério a presencialidade. Outro aprendizado importante está mais estritamente ligado à potencialidade de Paulo Freire para a compreensão sobre os espaços educativos como espaços de vida e trabalho, que clamam por humanização.

\section{REFERÊNCIAS}

BECKER, Fernando. Modelos Pedagógicos e Modelos Epistemológicos. In.: Silva, L.H., AZEVEDO, J.C. (org.). Paixão de Aprender II. Petrópolis: Vozes, 1995.

CANDAU, Vera. A Didática em Questão. Petrópolis: Vozes, 2004.

COSTA, Clarice. G.; FURTADO, Elaine. D. Situações Limites na Pedagogia do Oprimido e da Esperança: possibilidades para a formação do educador da EJA. V Seminário Nacional Formação de Educadores de Jovens e Adultos, 2015, Campinas. Disponível em: http://sistemas3.sead.ufscar.br/snfee/index.php/snfee/article/view/186. Acesso em: 20 fev. 2021.

FREIRE, Paulo. Pedagogia da Esperança: um reencontro com a Pedagogia do Oprimido. São Paulo: Paz e Terra, 2000.

FREIRE, Paulo. Pedagogia do Oprimido. Rio de Janeiro, Paz e Terra, 2005.

FREIRE, Paulo. O Papel do Trabalhador Social no Processo de Mudança. In.: Educação e Mudança. São Paulo: Paz \& Terra, $12^{a}$ edição, 1979. Disponível em:

https://construindoumaprendizado.files.wordpress.com/2012/12/paulo-freire-educacao-e-mudancadesbloqueado.pdf. Acesso em: 19 jan. 2021.

FREIRE, Paulo. Não há docência sem discência. In: Pedagogia da Autonomia: saberes necessários à prática educativa. São Paulo: Paz \& Terra, 1996a (Coleção Leitura). Disponível em: https://cpers.com.br/wpcontent/uploads/2019/09/9.-Pedagogia-da-Autonomia.pdf. Acesso em: 19 jan. 2021.

FREIRE, Paulo. Ensinar exige saber escutar. In.: Pedagogia da Autonomia: saberes necessários à prática educativa. São Paulo: Paz \& Terra, 1996b (Coleção Leitura). Disponível em: https://cpers.com.br/wpcontent/uploads/2019/09/9.-Pedagogia-da-Autonomia.pdf. Acesso em: 20 jan. 2021.

GOLDEMBERG, José. O repensar da educação no Brasil. Estudos Avançados, v. 7, n. 18, pág. 65-137, agosto de 1993. Disponível em: https://www.scielo.br/scielo.php?script= sci_arttext\&pid=S0103-40141993000200004. Acesso em: 14 dez. 2020.

GONZAGA, Marta. L.; CASTANHO, Maria. E.; MACHADO, Vera. L. de C. A articulação das dimensões política, ética e técnica como fomentadora da formação docente crítico -transformadora. In.: 
Leitura: Teoria \& Prática, v. 29, n. 56. 2011. Campinas: ALB, 2011. Disponível em: https://ltp.emnuvens.com.br/ltp/article/view/53/52. Acesso em: 4 jan. 2021.

LARROSA, Jorge B. Notas sobre a experiência e o saber da experiência. Revista Brasileira de Educação, Rio de Janeiro, n. 19. Jan/Fev/Mar/Abr, 2002.

RIOS, Terezinha. A. Compreender e ensinar: por uma docência de melhor qualidade. 5 ed. São Paulo: Cortez, 2006.

SAVIANI, Dermeval. Vicissitudes e perspectivas do Direito à Educação no Brasil: Abordagem Histórica e Situação Atual. Educ. Soc., Campinas, v. 34, n. 124, p. 743-760, jul.-set. 2013.

TAUCHEN, Gionra. et al. Situações-limite coletivas: a base de um projeto compartilhado. In.: $5^{\circ}$ Fórum de estudos: Leituras de Paulo Freire, 2003, Santa Cruz do Sul. Anais do $5^{\circ}$ Fórum de estudos: Leituras de Paulo Freire. Santa Cruz do Sul: Helga Haas, 2003.

UNIVERSIDADE FEDERAL DE MATO GROSSO. Conselho de Ensino, Pesquisa e Extensão. Resolução CONSEPE $\mathrm{n}^{\mathrm{o}}$ 32, de 8 de julho de 2020. Disponível em: https://www.ufmt.br/flexibiliza/docs/sobre/. Acesso em: 4 jan. 2021.

\section{Informações das autoras}

Geniana dos Santos

Universidade Federal de Mato Grosso

E-mail:genianaufmt@gmail.com

ORCID: https://orcid.org/0000-0001-6926-0132

Link Lattes: http://lattes.cnpq.br/2550888945457523

Maria Gabriela Ferreira Pereira

Universidade Federal de Mato Grosso

E-mail: gabrielaferreira1620@gmail.com

ORCID: https://orcid.org/0000-0002-1925-6925

Link Lattes: http://lattes.cnpq.br/6730451516181428 